\title{
What Factors Influence the Persistence of Female Genital Mutilation in Nigeria? A Systematic Review
}

\section{Emeordi Chidera*}

Medical and Dental Council of Nigeria, Anglia Ruskin University, Chelmsford Essex, Nigeria

"Corresponding author: Emeordi Chidera, Student, Medical and Dental Council of Nigeria, Anglia Ruskin University, Chelmsford Essex, Nigeria, Tel: +81-980522719; E-mail: Chidera.Emeordi@student.anglia.ac.uk

Received date: December 20, 2017; Accepted date: February 20, 2018; Published date: February 28, 2018

Copyright: $\odot 2018$ Chidera E. This is an open-access article distributed under the terms of the Creative Commons Attribution License, which permits unrestricted use, distribution, and reproduction in any medium, provided the original author and source are credited.

\begin{abstract}
Background: Female Genital Mutilation is the excision of any part of the female genital organs for non-medical reasons. According to the World Health Organization, approximately 200 million girls and women have been mutilated around the world. This practise is strongly tied to different cultural traditions. FGM has called for international recognition due to its violation of human rights. Over the past decades, there have been deliberations by researchers concerning the practice of FGM. Some have tried to understand the perception behind the practise of FGM from a Cultural Relativism aspect while others perceive it from an Ethical Relativism perspective. The Nigeria Demographic Health Survey, estimated that the prevalence rate of FGM was $24.8 \%$ in 2013 . Despite the interventions in place, there is still a persistence of FGM in Nigeria.
\end{abstract}

Objectives: 1) To Identify various contextual factors attributing to the persistence of FGM in Nigeria. 2) To recognise how these factors affect the Anti-FGM interventions in Nigeria. 3) To examine the attitudes and perception of the victims and other Nigerians towards FGM.

Data Sources: Medline, PubMed, Google scholar, CINAHL, Web of Science, Science Direct, Scopus and Cochrane.

Review methodology: A Systematic Review was used to carry out this research. It was used because of its ability to include both quantitative and qualitative studies, and due to its hierarchy of evidence. A narrative analysis was equally used to describe the studies which were included in this review.

Results: Three studies had similar findings concerning the practice of FGM in Nigeria which includes traditions, easing of childbirth and better marriage prospect, while 3 other studies concluded that FGM prevents sexual promiscuity. On the other hand, the remaining 3 studies had a different findings which was either religion, lack of awareness of the bans towards FGM and the sociodemographic and economic factors.

Conclusion: The ban that has been placed against FGM is just one aspect pointing Nigeria towards the right direction, however, Interventions need to be established which should include the local community and their leaders to effect a change. More primary research needs to be conducted in various states in Nigeria to understand the impact and progress of this law. Innovative ways of engaging a greater proportion of the affected population are also necessary.

Keywords: Tuberculosis; Female genital circumcision; Female cutting; Prevention

\section{Introduction}

Over a period of 40 years, FGM has been practised in some African countries. This practise is continually found in New Zealand, Australia, North America and Europe due to the increase in migration. The World Health Organization (WHO), United Nation for Children Emergency Funds (UNICEF) and the United Nations Population Fund (UNFPA) called for a joint eradication of FGM in 2007 [1].

Nigeria is one of the 30 countries, where FGM is practised. Statistics shows that the practice of FGM exists in other countries such as Iraq, Yemen and Indonesia. The WHO (2016), defines FGM as a surgical procedure which involves the excision of any part of the female genital organ for a non-clinical reasons. FGM is also known as Female Genital Cutting or Circumcision [2-4].

\section{Background}

There have been so many deliberations from various researchers concerning the theories around FGM practise. 3 areas of knowledge has been identified which are the history, human sciences (human rights, moral and legal principles) and ethics. The knowledge which are included in the history of FGM are tradition, religion and customs.

Some cultural anthropologist had tried to understand FGM from the perspective of cultural relativism, however, others have tried to understand from the ethical relativism perspective. From the cultural relativism point of view, FGM is a deep rooted, traditional practice whereas, from an ethical relativism, it identifies the concept of right or 
Page 2 of 4

wrong in a culture whilst, making a stronger and controversial claim [5-7]. The issue of FGM has called for international attention because of its health implications and increased risk which is posed to girls in the future. Cultural relativism consists of customs such as FGM which is acceptable in certain cultures, however, it is not ethically accepted in other cultures.

The attitudes and perception of FGM varies across Nigeria due to numerous factors, some of which would be explained based on the listed theories. "FGM is a tradition in transition". FGM is majorly performed by the traditional practitioners, however, there have been cases were FGM was performed by the health workers [8-10]. This is referred to as medicalization of FGM. Medicalization of FGM is a major concern towards FGM in Nigeria, this is an ethical misconduct. Moreover, a study conducted by Umar and Oche (2014), showed that some Professional Health Workers (PHW) encourage FGM.

Some parents believe that if the PHW carried out this procedure on their female children, there would not be any complication, this explains the patronizing of the PHW. The performance of FGM by these workers are attributed to reasons such as cultural beliefs, unawareness and as a means of getting extra payment, due to low salary payment $[11,12]$. FGM is performed mostly during infancy in some states, although, depending on the state of origin of a Nigerian girl, it can be carried out even up to adulthood.

The fact that this procedure is carried out on a child without her consent means that this is a violation of human rights. It is a sociocultural norm for elders to make a decision on your behalf in Nigeria. The Convention of the Rights of Child in 1989 refers to anyone below 18 years as a child (UNICEF, 2011) [13,14]. This Act for child protection is the same at that of Nigeria. In 2003, the Child Acts Rights was passed which makes the legal age of marriage 18. On a contrary, some states in Nigeria did not adopt this Act. Hitherto, these are parts of the reasons that makes FGM eradication difficult in Nigeria, due to the uneven implementation of laws.

Some African perceive FGM as not being an offence because it has been a tradition for generations. The particular number of women and girls that have undergone FGM is indefinite [4]. However, the UNICEF in the year (2016), estimates that more than 200 million girls and women have been mutilated around in 30 African countries including Nigeria. The practise of FGM is performed without anaesthesia, using tools such as knife or razor blades. The use of such instruments poses a threat for HIV infections and Hepatitis [15-17]. Despite the painful nature of FGM, it is seen as a festive ceremony in some communities in Nigeria. FGM includes 4 various types of which all are practised in Nigeria depending on the geographical location.

Type 1 and Type 2 are the most commonly practised in Nigeria. However, Type 3 and 4 are more prevalent in the northern states of Nigeria, and these are the most severe form of FGM [9]. The prevalence of FGM varies across different states in Nigeria. The NDHS (2014), estimates there is a $16 \%$ chance of continuance by the circumcised mothers. This is known as rationalism under the relativism of ethics. According to the NDHS, the prevalence rate of FGM was $24.8 \%$, which shows a decline of this practise [18-20].

Based on evidence, the decline in the prevalence rate of FGM in 2013 was attributed to increased awareness concerning FGM and it is estimated that FGM might reduce among the younger age groups. Among the various ethnic groups in Nigeria, this practice is much more prevalent among the Yoruba's and the Igbos with $58.4 \%$ and $51.4 \%$ respectively.

Recently, the states with high prevalence rates of FGM in descending orders are Osun, Ebonyi, Ekiti, Imo, Oyo, Kwara, Ondo, Edo, Delta and Kano. In 1999, Abia, Bayelsa, Cross River, Delta, Edo, Ogun, Osun and Rivers states passed a law against FGM. The constitution of the Federal Republic of Nigeria in 1999, was the foundation for the prohibition of FGM in Nigeria [21-24]. It states that "every individual is entitled to respect for the dignity of his person and accordingly, no person shall be subject to torture or to inhuman or degrading treatment".

In Edo state, anyone caught practising FGM would be subject to 6 months imprisonment and a fine of 1000 Nigerian Naira (\$10). In 2013, Nigeria joined other 17 African countries to ban the practice of FGM, the Maputo Protocol. A new legislation was however passed in the year 2015 called the Violence against Persons Prohibition Acts (VAPP) as per Law Pavillion in 2016.This illustrates that Nigeria is pointed towards the right direction in the eradication of FGM [25-27]. Despite the ban, evidence shows that FGM still persists in Nigeria. Moreover, Nigerians are concerned if this law would be enforced since there has been decreased outcomes from the previous laws in the states that adopted the policy [25-28]. There are short and long term health Implications of FGM which would be listed below (Table 1).

\begin{tabular}{|l|l|l|l|l|l|l|l|l|}
\hline \multirow{2}{*}{ Name of Talukas } & \multicolumn{2}{l|}{ Transect } & \multicolumn{2}{l|}{ Maximum } & \multicolumn{2}{l|}{ Minimum } & Mean & Comments \\
\cline { 2 - 9 } & Start No. & End No. & \multicolumn{2}{l|}{ Total } & \multicolumn{2}{l|}{ Erosion (m/year) } & Relative Erosion \\
\hline Keti-Bunder & 1 & 89 & 89 & 89.99 & -3.78 & 16.54 & Low \\
\hline Kharo-Chann & 90 & 189 & 100 & 108.38 & 14.9 & 63.79 & High \\
\hline
\end{tabular}

Table 1: Statistical values of linear regression rate of study area.

The treatment of FGM depends on the complications that mutilated women presents with. For instance, in a case of a woman with type 3 FGM, the procedure called deinfibulation is carried out. This surgery helps to relieve some of the problems caused by FGM [29-34].

The Millennium Developmental Goals concerning Maternal Mortality (MM) has not been met by Nigeria. Based on a study [8], part of his findings showed that FGM contributes to MM.

\section{Methodology}

\section{Study design}

The study design is a systematic review. It involves the collection and integration of both quantitative and qualitative data in answering a pre-designed research question. It was chosen, because of its strength 
of representation on both quantitative and qualitative research whilst lessening the restrictions of both approaches.

Secondly, it is a useful strategy to have a more complex understanding of research problems such as having a better understanding of the need for, and impact of an intervention program through collecting both quantitative and qualitative data overtime.

Additionally, a SR produces the most reliable source of evidence to guide practice and for making of decision. Based on the hierarchy of evidence, the SR is considered the most reliable form of evidence.

\section{Data abstraction}

The data extraction form was used to check the papers that was added to this SR. Afterwards, a data extraction table was created. It was carried out by the reviewer, however, there can be some limitations because it is normally supposed to be carried out by 2 or more reviewers.

\section{Data synthesis}

Based on the various studies which were collated by the writer, the narrative analysis would be used to analyse all the research findings. Narrative analysis is also known as a critical review which provides valuable summaries on a wide topic area. It can be influenced by their preferred theories, needs and beliefs.

\section{Results and Discussion}

\section{Description of the studies included}

After a thorough SR search, $n=9$ papers were identified. The research had been done at various locations. Studies was carried out in North-central, researches that were conducted in South-west includes that of.

While the remaining studies by was piloted in South-east, Northwest and South-south respectively. Moreover, this represents the geopolitical zones of Nigeria.

Consequently, the settings varies for all the studies. For instance, five studies was obtained in the Hospital, two studies were household surveys while the remaining studies was conducted at the Secondary Schools. Most of the studies were cross sectional studies which was either descriptive or prospective, whereas, only 1 study was a multi stage probability method.

The total population after the addition of the total sample size divided by the number of the papers $(\mathrm{N}=4423 / 9)$ is 491 . This was performed due to the heterogeneity of the sample size. From the research, the population ranged from the least to the maximum which is 95 to 1536 participants.

The studies by, had the same reports for reasons that attributes to the persistence of FGM which are tradition, easing of childbirth and getting better marriage prospect. Tradition was the most prevalent reason with $86.6 \%, 79.3 \%, 56.7 \%$ and $35.3 \%$ respectively. The findings in recent study however contradicts this, only $2.07 \%$ of the participants believed that FGM is practised due to tradition.

On the other hand, researches by had similar findings from the participants which are to prevent sexual promiscuity and ensure women are faithful in their marriages. The other perceived benefits by the participants is that it is necessary for womanhood with approximately $7.1 \%$. This shows, the level of misconceptions of the practice of FGM which would be passed on from one generation to another, if appropriate measures are not taken. Whilst, studies disputed the commonly-held belief that FGM prevents sexual promiscuity in women [16]. Based on his own findings, FGM promotes sexual urge and promiscuity. This is the only study that made this claim, so should be treated with caution until further research becomes available.

Additionally, in the study [10-12], a major concern was that most male teachers perceived FGM as a religious obligation to circumcise their daughters in the future. However, in the study [10], the findings concerning FGM and religion is that it is found across all types of religion. It is not an obligation for any particular religion.

Recent studies had a different findings which are the lack of awareness of the ban against FGM and its health complication with $91.3 \%$ and $79.9 \%$ [16]. This study shows that sociodemographic and economic factors such as the mother's age, occupation, education and monthly incomes subsidises FGC. From their findings, other factors that attributes to FGM persistence are illusory fears and beliefs, rationalization, Local traditions and perceived beliefs.

\section{Conclusion and Recommendations}

From the 9 papers that were reviewed, various contextual factors have been identified that are FGM perpetuators in Nigeria. FGM is a topic of silence among Nigerians, the chain of silence has to be broken particularly among men and boys because of their masculinity roles, for decision making in Africa. The lack of awareness of FGM bans and its health implications is what needs to be tackled urgently in Nigeria in order to save the future generation of girls and mothers from this torture.

The Health Belief Model would be used as a recommendation concerning FGM practises in Nigeria. With the perceived benefits of the prevention of FGM, the practise of FGM in Nigeria would be stopped gradually. Health Education and Health Promotion should be carried out across Nigeria using social media, television, radios and mass media and campaigns concerning the health implications and penalties for performing FGM. A door to door campaign should be carried out in Nigeria especially in communities were the prevalence of FGM is high.

The topic of FGM should be incorporated into the curriculum for teaching at primary and secondary schools. Much attention should be paid concerning the girl child education, this endeavours the development of a nation. This curriculum should encourage girls not to be afraid of reporting any suspicion from parents or family members to the school authorities from which the taskforce or relevant authorities would be contacted. The message that would be passed across during campaigns and in schools is "See it" "Hear it" and "Say it", this message means that if there is any suspicion at all concerning FGM, people should be encouraged to speak up by reporting to the relevant authorities. Money incentives should be given to those who report such incidences as a reward.

Education of older aged circumcised women cannot be overemphasized, to prevent the chances of their girls been mutilated. A lot needs to be done to evaluate the abandonment efforts with a methodological intervention evaluation. These innovations should discourse the role of the local community leaders in the implementation systems supporting FGM and be channelled by a theory of behavioural change, because they are perceived as role 
models, community leadership is key to reducing incidences and prevalence of FGM in Nigeria on a larger scale. FGM programmes needs to be moulded to each community specific need. The government should set up a taskforce against FGM for legal enforcement of the VAPP law. No feasible policy or program has been established for empowering practitioners of FGM, this means that the government should establish one for these practitioners. Additionally, to encourage Nigerians to speak out especially men and boys, alongside the leaders from various religious background to speak out about FGM implications to their congregants.

Innovative ways that encourage a large proportion of the affected community are required. For instance, Programs needs to be established for victims of FGM, as a means for reducing the psychological and traumatic effect (PTSD). A forum with the incorporation of cognitive behavioural therapy where victims from different ethnic groups and tradition would be able to discuss about their lived experiences and encourage one another. This form of therapy for circumcised women should be supported by NGOs and the Federal Government of Nigeria. With such programs, it would help aid change the perception and encourage Nigerians to speak up about FGM. A policy that protects the rights of children should be adopted such as the social care and welfare in collaboration with the health system of Nigeria.

\section{References}

1. Abayomi AA, Olabode T (2013) Domestic violence and death: Women as endangered gender in Nigeria. Amer J Socio Res 3: 53-60.

2. Abdur-Rahman LO, Musa OI, Oshagbemi GK (2012) Community-based study of circumcision practices in Nigeria. Annals Trop Med Pub Heal 5: 231.

3. Abdulcadira J, Margairaz C, Boulvain M, Irion O (2011) Care of women with female genital mutilation/cutting. Swiss Med Wkly 140: 131-137.

4. Abolfotouh SM, Ebrahim AZ, Abolfotouh MA (2015) Awareness and predictors of female genital mutilation/cutting among young health advocates. Int J Women's Health 7: 259-269.

5. Achakpa N, Grace A (2016) Sex stereotyping in advertising and effects on the self-esteem of Nigerian women. J Med Comm Stud 8: 1-7.

6. Adayonfo E, Adewole A (2017) Socio-cultural barriers against the prevention of female genital mutilation.

7. Adegoke A, Atiyaye F, Abubakar A, Auta A, Aboda A, et al. (2015) Job satisfaction and retention of midwives in rural Nigeria. Midwifery 31: 946-956.

8. Adelufosi A, Edet B, Arikpo D, Aquaisua E, Meremikwu MM, et al. (2017) Cognitive behavioral therapy for posttraumatic stress disorder depression, or anxiety disorders in women and girls living with female genital mutilation: A systematic review. Int J Gynecol Obstet 136: 56-59.

9. Adeniran A, Fawole A, Balogun O, Ijaiya M, Adesina K, et al. (2015) Female genital mutilation/cutting: Knowledge, practice and experiences of secondary school teachers in North Central Nigeria. S Afr J Obstet Gynaecol 21: 39-43.

10. Adeniran AS, Ijaiya MA, Fawole AA, Balogun OR, Adesina KT, et al. (2016) Attitudes to female genital mutilation/cutting among male adolescents in Ilorin, Nigeria. S Afr Med J 106: 822-823.

11. Adeyinka RA, Adedotun OO, Asabi O (2012) Knowledge and practice of female circumcision among women of reproductive ages in South West Nigeria. IOSR Journal of Humanities and Social Science 2: 38-45.

12. Ahanonu E, Victor O (2014) Mother's perceptions of female genital mutilation. Heal Edu Res 29: 683-689.

13. Rezaee AF (2013) Female genital mutilation experiences of somali women living in Sweden. University of Gothenburg, Sweden.
14. Ajite A, Ogundare E, Oluwayemi O, Agaja O, Babatunde A, et al. (2016) Prevalence of female circumcision among children presenting in a semiurban Tertiary Teaching Hospital in South West Nigeria. J Med Medical Sci 7: 30-37.

15. Akosile A (2016) Nigeria: Fighting female genital mutilation on all fronts.

16. Al-Mujtaba M, Cornelius LJ, Galadanci H, Erekaha S, Okundaye JN, et al. (2016) Evaluating religious influences on the utilization of maternal health services among Muslim and Christian women in North-Central Nigeria. BioMed Res Int 3645415.

17. Amusan OA, Asekun OE (2008) Knowledge, beliefs, and attitudes to female genital mutilation (FGM) in Shao community of Kwara State, Nigeria. Int Q Comm Heal Edu 27: 337-349.

18. Ani KJ (2012) Violent traditional gender practices and implications for nation building Process in Nigeria. Public Policy and Administration Research 2: 44-56.

19. Ashimi A, Aliyu L, Shittu M, Amole T (2014) A multicentre study on knowledge and attitude of nurses in northern Nigeria concerning female genital mutilation. Euro J Cont Repro Heal Care 19: 134-140.

20. Ashimi AO, Amole TG (2015) Perception and attitude of pregnant women in a rural community north-west Nigeria to female genital mutilation. Arch Gynecology and Obstetrics 291: 695-700.

21. Ashimi AO, Amole TG, Iliyasu Z (2015) Prevalence and predictors of female genital mutilation among infants in a semi urban community in northern Nigeria. Sexual \& Reproductive Healthcare 6: 243-248.

22. Ayenigbara G, Aina S, Famakin T (2013) Female Genital Mutilation: Types, Consequences and Constraints of Its Eradication in Nigeria. IOSR J Dent Med Sci 1: 7-10.

23. Berg RC, Denison E (2012) Interventions to reduce the prevalence of female genital mutilation/cutting in African countries. Campbell Systematic Reviews.

24. Berg RC, Denison E (2013) A tradition in transition: factors perpetuating and hindering the continuance of female genital mutilation/cutting (FGM/C) summarized in a systematic review. Health care for women international 34: 837-859.

25. Bettany S, Cronin P (2012) How to do a Systematic Literature Review in Nursing. A Step-by-Step Guide, Open University Press: Nurse Education in Practice.

26. Billet B (2016) Cultural relativism in the face of the West: the plight of women and female children.

27. Bohren MA, Vogel JP, Tunçalp Ö, Fawole B, Titiloye MA, et al. (2016) "By slapping their laps, the patient will know that you truly care for her" A qualitative study on social norms and acceptability of the mistreatment of women during child birth in Abuja, Nigeria. SSM-Population Health 2: 640-655.

28. Chukwuezi C (2010) Socio-cultural factors associated with maternal mortality in Nigeria. Res J Soc Sci 1: 22-26.

29. Creswell JW (2013) Research design: qualitative, quantitative, and mixed method approaches. SAGE Publishing, Thousand Oaks.

30. Cross TP, Mathews B, Tonmyr L, Scott D, Ouimet C (2012) Child welfare policy and practice on children's exposure to domestic violence. Child Abuse Negl 36: 210-216.

31. Dalal K, Lawoko S, Jansson B (2010) Women's attitudes towards discontinuation of female genital mutilation in Egypt. J Inj Viol Res 2: 41-45.

32. Dionisio P (2016) Female genital mutilation in Nigeria: Is it over? University of Florence, Italy.

33. Effa E, Ojo O, Ihesie A, Meremikwu MM (2017) De-infibulation for treating urologic complications of type III female genital mutilation: A systematic review. Int J Gyn Obst 136: 30-33.

34. Enwereji E, Enwereji K (2013) Towards the abandonment of female genital cutting in communities in Abia State: Initiatives in Nigeria. Abia State University, Nigeria. 